\section{FUNDAMENTOS Y EXPERIENCIAS DE LA DIVULGACIÓN \\ CIENTíFICA EN SANTIAGO DE GUBA}

\author{
Giovanni L. Villalón García*
}

\section{Resumen}

Son muchos los elementos y procesos que intervienen en la formación de una cultura científica, generadores de las más disímiles posiciones, a veces contradictorias y hasta antagónicas por lo que se hace necesario dilucidar las diferencias entre información científica, divulgación científica, comunicación científica y también de socialización de la ciencia.

En el texto se hacen las reflexiones teóricas y metodológicas sobre la comunicación social de la ciencia y la divulgación científica, y se indica que es necesario identificar las áreas de desarrollo científico - técnico, que abran camino de oportunidades de investigación y que estimulen la participación social, como resultado del fomento de una cultura científica sistematizada y coherente que se inserte en el desarrollo local.

El artículo presenta la sistematización del trabajo que se desarrolla en Santiago de Cuba para impulsar la socialización de la ciencia, destacando espacios institucionales como el "Museo de Historia Natural Tomás Romay", el "Jardín de los Helechos", el "Salón de la Ciencia" así como la actividad "Desempolvando", el proyecto"Sendero de las Personalidades de las Ciencias" y los programas de televisión y radio "La Historia y sus protagonistas", "expedición", "I + D" y " La ciencia entre nosotros". Se precisa sobre las acciones con las que se puede dinamizar la cultura científica y acerca del ejercicio profesional de la divulgación científica.

\section{Palabras Clave:}

Divulgación científica, comunicación científica, cultura científica territorial, desarrollo local, Santiago de Cuba.

\section{FOUNDATIONS AND EXPERIENGES OF SEIENTIFIC DISSEMINATION IN SANTIAGO DE CUBA}

\author{
Giovanni L. Villalón García*
}

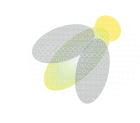

\section{Sumary:}

There are many elements and processes involved in the formation of a scientific culture, they generate the most different positions, sometimes contradictory and many times antagonistic for that reason is necessary clear up the differences between scientific information, scientific dissemination, scientific communication and also socialization of science.

The text makes theoretical and methodological reflections about the social communication of science and scientific dissemination and suggests that is necessary to identify areas of development scientific - technical, to open way of opportunities of investigation and to stimulate social participation, as result of the furtherance of a systematized and coherent scientific culture that insert in local development.

Thearticle presents the systematization of the work that takes place in Santiago de Cuba to boost the socialization of science, highlighting institutional spaces like "Museo de Historia Natural Tomás Romay", the "Jardín de los Helechos", the "Salón de la Ciencia" as well as the activity "Desempolvando" the proyect "Sendero de las Personalidades de las Ciencias" and the tv and radio programs "La Historia y sus protagonistas", "expedición", "I + D" and "La ciencia entre nosotros". Specifying about the actions with which can effectuate the scientific culture and about the professional practice of scientific dissemination.

\section{Keywords:}

Scientificdissemination,scientificcommunication, scientific territorial culture, local development, Santiago de Cuba. 


\section{Introducción}

La frase: "...amenizar la ciencia es generalizarla," escrita por el Héroe Nacional cubano José Martí [1] marca el propósito cultural general de un proyecto educativo a nivel social que de hecho reconoce el valor de que todos los seres humanos sean portadores de los nuevos conocimientos que generan las ciencias. De ahí que se considere que:

"La ciencia solo es verdaderamente cierta cuando se pone al servicio de la comunidad y ésta la acoge, se nutre de ella, la hace parte de su cultura y la lleva en el corazón." [2]

El planteamiento defiende la idea de la socialización de la ciencia, como expresión de una cultura en la que todos tenemos un rol. Y con ella se protege no solo el conocimiento en sí, sino también a los creadores, la sociedad, los valores, la relación con la naturaleza y con el potencial humano, el cual de alguna manera confirma las esperanzas en un mundo mejor, donde se alcance la verdadera integración hombre - naturaleza.

Por lo anterior surgen preguntas tales como: ¿Quién debe dedicarse a la difusión de la ciencia? ¿Solo los profesores universitarios? ¿Qué papel juegan los periodistas? ¿Cuál debe ser el rol de los propios investigadores? ¿Pueden ellos protagonizar programas de radio, de TV, o escribir en la prensa artículos científicos? ¿O deben limitarse a ser asesores de los periodistas o de los profesionales de la comunicación social o divulgación científica? ¿Un profesional sin experiencia investigativa que asumiera la divulgación científica puede ser tildado de intrusismo? ¿Esta labor debe ser profesionalmente acreditada? $Y$ finalmente, otro interrogante: ¿Cuál es la ética que orienta el proceso de la divulgación científica? Preguntas que constituyen problemáticas no resueltas definitivamente, y que quizás, nunca se llegue a un consenso resolutivo sobre este actuar profesional.

La divulgacióncientífica esun mediorelativamente eficaz para compensar las carencias en que se mueve la ciencia dentro del contexto actual y también los problemas derivados del gigantesco crecimiento científico de nuestro tiempo. Surge así la necesidad de profesionalizar la divulgación científica en los medios informativos y de reforzar en ellos la presencia de los divulgadores.

Como comunidad profesional debemos tomar partido y ser consecuentes con ello, teniendo como sostén la labor formativa, la veracidad de la información, la asequibilidad del contenido, el respeto por el conocimiento y sus fuentes originarias, así como el valor de los conocimientos para mejorar la comprensión de la vida, las relaciones sociales y las alternativas de desarrollo futuro. Sin embargo, los espacios de información y debates propiciados en Santiago de Cuba desde hace unos pocos años, constituyen un buen indicio de lo que se ha andado, sobre todo en el sentido de la comprensión y dinámica de la divulgación científica.

\section{Comunicación Social de la Giencia}

En la concepción de los proyectos de investigación, la divulgación científica cobra más protagonismo pues se considera [y se exige], como una tarea propia de cada proyecto. Sin embargo, se carece del tiempo necesario o de recursos humanos especializados para acometer este tipo de actividades, aunque también ocurre más claramente que se adolece de un criterio favorecedor de la divulgación científica como parte de las acciones propias de cada proyecto y de las responsabilidades de los investigadores.

En este contexto de alguna manera favorable, se precisa que la "Comunicación Social de la Ciencia" o "Divulgación Científica", consiste en desarrollar metodologías, materiales y actividades que transmitan estos conocimientos al público general, de una manera accesible, adaptada y entendible, añadiéndole un componente lúdico y de diversión para motivar y facilitar la asimilación de los conceptos divulgados, dada la cierta especificidad que poseen estos conocimientos, [alta ciencia, tecnología de última generación] con el propósito de que individuos de diverso nivel de instrucción, se apropien de los resultados, que se suponen mejoren su vida cotidiana y en el futuro se conviertan en innovadores, por lo que debe un aprendizaje eficaz, preventivo y estimulador de la creatividad.

Vladimir de Semir, uno de los abanderados de la comunicación científica en España, profesor de Periodismo Científico en la Universitat Pompeu Fabra, que dirige el Observatorio de Comunicación Científica y Médica, en una entrevista expresó su valoración del estado de la divulgación científica en los medios de comunicación convencionales:

\footnotetext{
"Durante años hemos luchado por un aumento de la cantidad de información científica en los medios. Hoy tenemos que empezar a luchar por una mayor calidad, lo que puede comportar una menor cantidad aunque parezca una contradicción. Necesitamos información que se convierta en conocimiento y eso sólo se alcanza con análisis, contexto y voces expertas, además de las exclusivamente periodísticas." [3]
} 
Señala además que la divulgación científica se ha convertido en una herramienta estratégica no sólo cultural de la sociedad del conocimiento, en la ecuación clave de dicha sociedad, que es I+D+i [investigación, desarrollo, innovación], que necesita una cuarta variable, el catalizador $C$, de la Cultura Científica, mecanismo que garantiza el impacto y la sostenibilidad de ese conocimiento y con ello la tecnología que lo acompaña.

Como puede apreciarse, la comunicación y divulgación científica tienen espacios de desarrollo, consustanciales a la especialización que va teniendo la propia producción de los conocimientos, de la ciencia y la tecnología, por lo que es complejo su abordaje teórico y práctico.

¿Cuáles son los principales problemas que complejizan la divulgación de las ciencias en particular? Es evidente que no hay un conjunto de causas o problemas bien definidos, sin embargo, queremos aproximarnos a su definición en aras de que puedan ser utilizados para los debates que se generarán, y en lo adelante estructurar acciones que aminoren su incidencia y así contribuir a la efectividad del demandado fomento y desarrollo de la cultura científica. Sin ánimo de cerrar el tema y sin acudir a expresiones concluyentes, en la práctica de nuestro oficio hemos observado las siguientes problemáticas:

- Complejidad de los conocimientos científicos y tecnológicos de rápido agotamiento a escala universal, conducente a la superación de lo aportado por nuevas investigaciones en poco tiempo.

- Enfoques que consideran a la ciencia como una actividad para un grupo privilegiado de personas de inteligencia superior.

- Complejidad de la terminología especializada por áreas y especialidades del conocimiento científico.

- Diversidad de aparatos conceptuales que generan cierta incertidumbre en la veracidad de las conclusiones teóricas que aportan las investigaciones.

- Impresionante velocidad en el uso de las nuevas tecnologías que soportan el desarrollo científico técnico, lo cual exige mejores herramientas de la información, cada vez menos tradicionales y más complejas para su uso adecuado.

En este sentido, afirmamos que el éxito en la divulgación científica radica en la constancia de quienes la realizan, porque hay que acostumbrar a los públicos a que en determinados medios y espacios puede encontrar información sobre ciencia y tecnología, acorde a su necesidad.

En México se reconoce el valor de la comunicación científica; sin embargo, Estrada Martínez, investigador y divulgador de la ciencia, asegura que en la Universidad Nacional Autónoma de México- UNAM, como en muchos recintos de éste hermano país, quienes ejercen la divulgación de la ciencia lo hacen de manera marginal y complementaria, no es realmente prioritario. $Y$ dice categóricamente:

"Para mucha gente, esto sigue siendo el patito feo; la cosa que a nadie le preocupa mucho"[4].

Por otra parte, se conoce que se ha hecho mal uso de la divulgación, a veces de forma inconsciente, sin intenciones premeditadas, pero en otras, se promueven con la deliberada intención de deformar una determinada idea que sostiene la ciencia con sólidos y coherentes argumentos, con el fin de engañar $u$ obtener ganancias económicas con la no aplicación práctica de tales fundamentos.

Ejemplos muy diversos de los anterior se pudieran situar, pero solo se menciona lo que ha ocurrido con determinados medicamentos salidos de los laboratorios de las transnacionales. No son pocas las situaciones en las que un medicamento no ha probado su verdadera efectividad en bien de la salud humana, pero las campañas publicitarias lo hacen valer, como sostén de una manipulación mediática que garantiza el mercado y con ello las ganancias.

En este sentido se obvia el valor que tiene la medicina natural y tradicional por su bajo costo y fácil utilización, hiperbolizando el impacto de los medicamentos de origen sintético. Todo es ganancia y para ello se manipulan los resultados científicos. De ahí que se deba tener claridad en relación con que la divulgación científica mal practicada puede ser engañosa. Su base puede ser de diferente origen, pues en ocasiones se divulgan trabajos científicos por personas que no son expertas en el tema que divulgan y desde ahí se pueden realizar inadecuadas interpretaciones. En otras ocasiones se observan trabajos de divulgación escritas por personas parcializadas que se aferran a posiciones epistemológicas que limitan la comprensión de los procesos a los que se refieren.

Un aspecto a tener en cuenta en estos procesos es que el reconocimiento de los errores en la publicación, suele resultar difícil para una persona sin adecuada formación científica. Identificar y rebatir los artículos o documentales falsos o fraudulentos demora el tiempo suficiente como para que muchas personas pasen por el engaño y asuman esas posiciones y se aferren a ellas y las defiendan. Es un proceso complejo pues no todo el mundo ni siquiera la comunidad científica lee todo cuanto se publica y se ha descubierto, con el paso de los años, que incluso algunos científicos han logrado engañar a la comunidad académica respecto a los resultados de sus trabajos. 
En otras ocasiones los resultados de investigaciones científicas son presentados por la prensa general sin el debido contexto o simplificándolos en exceso.

Estrada reconoce que "la divulgación también puede sobrepasar los límites de la ciencia formal y acercarse peligrosamente hacia las pseudociencias, y abordar temas más sensacionalistas como las dietas milagro, la teoría del caos y los viajes en el tiempo" [5]. Pero a pesar de estas realidades la comunicación y divulgación científica son una necesidad insoslayable en la vida moderna. Y alrededor de esta problemática se manifiestan diversas situaciones que requieren de nuestra atención, tanto en el orden conceptual como de su aplicación práctica y su impacto en la sociedad actual.

El concepto base de toda esta labor es la cultura científica. Según la Real Academia Española, la Cultura puede ser el "conjunto de modos de vida y costumbres, conocimiento y grado de desarrollo artístico, científico, industrial, en una época, grupo social, etc.". La misma institución define Ciencia como "conjunto de conocimientos obtenidos mediante la observación y el razonamiento, sistemáticamente estructurados y de los que se deducen principios y leyes generales". Por todo ello, como concepto general e integrador se puede considerar la cultura científica como la síntesis de conocimientos no especializados de las diversas ramas del saber científico, que propician la formación de una base teórica que facilita la valoración sobre cada una de ellas y que en un sentido ideal, cualquier persona instruida debería poseer.

Los otros conceptos que caracterizan esta labor formativa son: comunicación, difusión, divulgación, información, diseminación, todos ellos orientados a la cultura científica. La transmisión de la información ocurre como resultado de la actividad científica informativa, es decir, uno de los tipos de actividad incluida en la actividad científica y que es indispensable para la unidad y efectividad de la ciencia contemporánea. Por consiguiente, el saber es información científica en un sentido amplio, es decir, cualquier representación lingüística, sin que necesariamente se encuentre generalizada y sistematizada en alto grado. Este grado lo diferencia del reflejo sensorial, que no constituye conocimiento científico, a pesar de que éste se forma en base al conocimiento sensorial. Al mismo tiempo el conocimiento científico como resultado del reflejo y de la actividad científico investigativa, constituye información científica primaria para la actividad científicoinformativa. Al profesional de la información le interesa básicamente la documental, que puede transmitirse de un científico a otro [consumidor de información].
El proceso de transmisión es el mecanismo principal que transforma el conocimiento científico [como información científica] en información científico técnica en un sentido estrecho, es decir, como se emplea en la práctica social por los profesionales de la información.

Desde la posición de la actividad científica informativa, la información científica no es simplemente conocimiento como representación lógica, verbal, sino conocimiento científico transmitido a un destinatario, a un consumidor.

La difusión por su parte, se refiere, según Pasquali [1979], al envío de mensajes elaborados en códigos o lenguajes universalmente comprensibles, a la totalidad del universo perceptor disponible en una unidad geográfica, sociopolítica, cultural, etc. Este es el caso de la difusión de las investigaciones entre biólogos, sociólogos, etc. Lo que caracteriza a este tipo de difusión es que presupone que el destinatario de un mensaje conoce el tema, aunque no sea un experto. Por ello, muchos califican este tipo de comunicación como horizontal [6]. Por otro lado, se entiende por diseminación el envío de mensajes elaborados en lenguajes especializados a perceptores selectivos y restringidos. Se despliega sobre todo en el personal de la información que tiene la responsabilidad social de ordenar, clasificar y dar a conocer la información científica recibida.

Entonces, ¿qué es la comunicación científica? Es éste un concepto genérico del proceso de formación de la cultura científica. Se despliega y concreta cuando existe un intercambio dentro de la comunidad científica y se manifiesta por diferentes canales, escrito, verbales y audiovisuales e informáticos en general. Se puede ilustrar cuando dos especialistas de una misma disciplina [que trabajan en un mismo tema o forman parte de un mismo grupo de investigación o comparten un mismo laboratorio], funcionando simultáneamente como emisores, receptores y medios vivos, intercambian ideas de manera oral o escrita.

La densidad conceptual e informativa de lo que hablan es alta y el lenguaje muy cifrado, especializado, con una codificación muy "familiar" y por tanto asequible, genera manifestaciones de una terminología entendible sólo en ámbitos especializados o exclusivos. Por ello se intercambia conocimientos, experiencias y formas de pensamiento que están brotando en vivo, como expresión del producto fresco de la investigación científica. La divulgación científica por otra parte es la transferencia social de la producción científica, independiente del nivel cultural del destinatario.

Sinos atenemos al origen de la palabra retomamos que este concepto define la raíz "vulgo" [del latín vulgus, el común de la gente popular] como la interpretación y popularización del conocimiento científico al alcance social general. 
De otra manera, la divulgación científica es el conjunto de actividades que interpretan y hacen accesible el conocimiento científico al público general, es decir, a todas aquellas labores que llevan el conocimiento científico a las personas interesadas en entender o informarse de ese tipo de conocimiento.

La divulgación pone su interés no sólo en los descubrimientos científicos del momento, sino también en teorías más o menos bien establecidas o aceptadas socialmente o incluso en campos enteros del conocimiento científico.

Manuel Calvo Hernando [2006] considera que la divulgación es el envío de mensajes elaborados mediante la transcodificación de lenguajes crípticos a lenguajes omnicomprensibles, a la totalidad del universo perceptor disponible. Se considera que en la divulgación se parte de que el mensaje se dirige a un público heterogéneo, formado por personas de muy distinta preparación. Para muchos estudiosos del tema, la especialización de la ciencia contemporánea hace que la comunicación entre científicos de distintas disciplinas, pueda ser considerada también una labor de divulgación.

El uso más frecuente de la expresión "divulgación" está en la comunicación del científico con el público en general, por lo que esta modalidad puede llamarse comunicación vertical [7]. Es por eso que se considera que la divulgación científica es el proceso de transmitir al gran público, en lenguaje accesible, decodificado, informaciones científicas y tecnológicas. El periodismo científico es, entonces, la misión del periodista en pos de divulgar a través de los medios de comunicación de masas y en lenguaje accesible, informaciones científicas y tecnológicas. Lo que le distingue de la divulgación no es el tema, sino el vehículo utilizado. De ahí que se comprenda que el concepto de divulgación científica es más amplio que el de periodismo científico. El primero comprende todo tipo de actividades de ampliación y actualización del conocimiento.

En el orden histórico la divulgación se origina cuando la ciencia brinda sus aportes a la cultura y deja de estar reservada exclusivamente a los propios miembros de la comunidad investigadora o a las minorías que dominan el poder, la cultura o la economía. Para el equipo editorial de la revista mexicana Ciencias [2009] la divulgación es:

\footnotetext{
"Un medio para integrar conocimientos, acercar disciplinas, vincular la ética al quehacer científico y sobre todo acortar la distancia entre el público y los expertos. La imagen del mundo que la ciencia ha construido sólo puede ser recreada por medio de la confluencia de las diversas ramas del conocimiento".
}

En este trabajo se precisa que si bien la fuente de información científica es una sola, o sea, los hechos y aportaciones de los científicos, la divulgación científica puede tener variadas formas de presentación. En este sentido, se hace alusión a las diferentes finalidades, géneros periodísticos y acciones sociales. Digamos que las finalidades pueden ser solo atraer en lo fenoménico a un determinado acontecimiento científico o por el contrario comprometer a los destinatarios con los contenidos que se van a presentar por determinadas vías de divulgación.

Otras formas que se han materializado como espacios sociales para la divulgación científica son las instituciones [escuelas, centros de investigación y universidades], espacios socioculturales [museos y bibliotecas, entre otros]; también la dinámica de diferentes formas de divulgación [conferencias, cursos, talleres, coloquios, etc.] así como el uso de los medios de comunicación masiva [revistas, el cine, la radio, el diario, la TV]. En este entorno un importante papel lo juega el uso de la informática, ya sea internet como el correo electrónico y las bases de datos.

\section{¿Quiénes deben divulgar?}

Una vez sistematizada la fuente de la cultura científica como creación humana, se necesita dilucidar ¿quiénes deben divulgar? Se parte de reconocer que la historia de la divulgación científica tiene mucho que ver con la propia gestión de los científicos de antaño, que durante años pusieron su interés con más o menos intensidad en que la sociedad conociera de sus ideas y resultados investigativos. Es este uno de los aspectos más polémicos que se manifiestan en esta actividad formativa de la cultura científica, o sea, el referido a quiénes deben divulgar.

En general se tiene en cuenta el trabajo de varios profesionales que desarrollan determinadas actividades que de alguna manera favorecen la comunicación y divulgación científica. Nos referimos a los periodistas, los profesores y maestros, los especialistas en trabajo social y cultural, así como los graduados en comunicación social. Por supuesto, no debemos olvidar a los propios investigadores.

Son éstos los profesionales que más están en condiciones de desarrollar una buena y efectiva labor de formación de una cultura científica. Esto no significa, sin embargo, que los demás profesionales no lo puedan hacer, solo que los investigadores por razones de sus especialidades tienen un terreno mejor abonado para esas finalidades formativas. La doctora Luisa Massarani [8] refiere que el perfil de la persona que vaya a divulgar la ciencia es amplio, y puede ser desde un periodista, un científico o hasta un artista. 
"Lo que sí importa es que tenga interés en reducir la brecha entre la ciencia y la sociedad".

Por su parte, Lisbeth Fog [9] coincide con Massarani, al sostener que la divulgación de la ciencia la puede hacer cualquier profesional capacitado en la entrega de la información, incluso los investigadores que hacen sus trabajos en -por ejemplo- salud pública, investigación social o ingeniería.

"El divulgador puede ser cualquier profesional, pero cuando entramos al periodismo científico, al oficio que es, entregar noticias, los periodistas tienen esa responsabilidad".

De ahí que este autor comparta las posiciones referidas a que aunque los periodistas tienen esa responsabilidad, no significa cerrarles las puertas a otros profesionales que demuestran ser talentosos en la divulgación científica al escribir o al realizar programas interesantes de radio y televisión usando las técnicas del periodismo.

En esta temática del protagonismo profesional de los divulgadores científicos, hay un aspecto que no se puede soslayar y es el referido a la formación especializada de los comunicadores y divulgadores científicos. Si bien abogamos por la ampliación de la cantera o la base profesional de quienes pueden ejercer la divulgación científica, no se puede obviar la necesidad de la formación especializada en aras de lograr y mantener un nivel de calidad y sostenimiento de la ética en el trabajo. Es que la inmensa mayoría de los que se dedican a la comunicación y divulgación científica llegan a ella de forma casual o sencillamente por una decisión individual, cuando la comprensión de la necesidad de llevarla a cabo, el interés por contribuir a dinamizar en la sociedad la cultura científica y las coyunturas de trabajo se lo han propiciado. Pero una vez enrolados en la labor divulgativa se deberá reflexionar en la necesidad de una preparación especial para hacer una labor de calidad y efectiva.

Esta realidad profesional ha sido analizada por especialistas en diversas partes del mundo. Al decir de Estrada Martínez, quien fuera director del Centro Universitario de Comunicación de la Ciencia [CUCC], y el primer mexicano en recibir el premio Kalinga que otorga la Organización de las Naciones Unidas para la Educación, la Ciencia y la Cultura, aunque en México cada vez más personas se dedican a la divulgación científica, en realidad son pocas las que tienen una formación que les permita profundizar en sus labores [10]. Por otra parte, Drucker Colín comparte la idea de profesionalizar la divulgación científica. Es de la opinión de que "En realidad, no son los científicos [como él mismo] quiénes deberían dedicarse a la divulgación". La divulgación debe recaer en aquéllos que estudian comunicación y deciden orientarse hacia la comunicación de la ciencia.
En general se reconoce que durante años fue un hacer de profesionales que poco a poco lo han convertido en un trabajo especializado, hasta alcanzar la condición de ser una actividad esencial en la cultura social, desarrollada principalmente por científicos u hombres ilustrados, los cuales tenían o iban desarrollando las habilidades comunicativas. "Se hacían entender", como se dice coloquialmente. Es tal su repercusión que observando el trabajo sobre la divulgación científica en México, Ruy Pérez Tamayo al preguntarse ¿Qué debe perseguirse con la divulgación científica?, asumió que "el objetivo es muy claro: incorporar el espíritu de la ciencia en la cultura nacional" [11].

En esta labor hay que tener en cuenta varios aspectos que son trascendentales para la efectividad de la labor divulgativa. Exponemos tres elementos que a nuestro modo de ver, son los que centran la atención de la calidad en la labor profesional de divulgación de la ciencia.

El contenido mismo de la ciencia y la tecnología constituye en sí la aportación y está escrito con la visión del investigador, es la fuente de información sobre la cual se sustenta la cultura científica. El asunto es cómo llevarlo a procesos de divulgación científica. Es ahí donde entran al ruedo el talento, la sagacidad pero sobre todo la preparación de los que se dedican a la comunicación y divulgación de estos contenidos. En este sentido el segundo aspecto a tener en cuenta es el nivel de asequibilidad que se deberá lograr con la estructuración del mensaje. Para ello los divulgadores de la ciencia y la tecnología deberán observar los siguientes aspectos:

- Terminología que emplea el investigador y la utilización de sinónimos que acerquen el contenido a la cultura del destinatario. Es en sí, la codificación que va a emplear en la presentación del mensaje, las imágenes a mostrar, las interacciones conceptuales, etc. Todo ello sin demeritar la calidad del mensaje original de la fuente, lo cual requiere de un estudio profundo del trabajo y la interpretación adecuada.

Es un momento trascendental que garantiza la comunicación con el auditorio y exige del divulgador una preparación exhaustiva, que no solo basta con el estudio de la fuente básica sino de los contenidos complementarios que dan mayor amplitud al manejo de los contenidos, situaciones y ejemplos.

- Utilizar expresiones que muestran la cercanía de los contenidos del trabajo a divulgar con la vida de los destinatarios, sus profesiones, sus actividades cotidianas, de manera que se sientan parte del proceso que se explicará.

- Llamar la atención a determinados problemas que exigen en la realidad y que la propuesta que se le presentará constituye la solución, 
parte de ella y una forma de interpretación de las manifestaciones del proceso que se estudia. Por tanto, que ayudará a los destinatarios a comprender el proceso, su dinámica y que ellos formen parte de las alternativas de solución.

- Respetar los códigos de la información referida a la relación figura - fondo, la unidad imagen palabra, las normas de la oratoria, las normas e intenciones del uso de los signos de puntuación, etc.

Para lograr lo anterior es necesario que el divulgador de la ciencia y la tecnología tenga bien definido el público para el cual va a escribir o visualizar, a saber: el nivel cultural que posee, los conocimientos previos que sobre el tema se le ha brindado, la edad promedio que tiene e incluso el nivel profesional. También la finalidad que tiene el investigador con la publicación de los resultados investigativos.

\section{El divulgador de la ciencia y la tecnología como profesional}

Sin dudas en los últimos años se observa un panorama muy diferente, cada vez más dinámico y variado en cuanto a la presencia de la información científica en los diferentes espacios sociales, desde los medios de difusión masiva hasta el incremento de los eventos, los debates, y un ligero aumento de la presencia de profesionales [científicos y tecnólogos en los espacios de socialización] en las instituciones. Si bien se han publicado muchos trabajos sobre la comunicación y divulgación científica, sobre todo desde la aparición de la internet y sus bondades informativas, aún es necesario una calificación profesional que encamine a los que se quieran dedicar [o incluso a los que ya lo hacen] a esta labor, a hacerlo bien y con responsabilidad ética, sobre la base de una acreditación especializada o específica.

La acreditación de la formación especializada en la divulgación científica no es un proceso exento de dificultades y obstáculos para su materialización. En general, la acreditación de los comunicadores científicos se concretan en cursos breves o de postgrados, conferencias y en un máximo nivel de diplomado. En particular, la UNAM cuenta con un diplomado en divulgación de la ciencia, además una maestría y un doctorado en filosofía de la ciencia con una línea en comunicación de la ciencia. No obstante, Luis Estrada considera que sería muy importante que en la UNAM se creara un posgrado especializado en divulgación de la ciencia.

No obstante, debemos confirmar que la mayor calificación profesional para este ejercicio por la cultura científica es el esfuerzo personal, constante y sistemático de los propios divulgadores científicos. La auto superación y el compromiso por hacerlo bien son la clave para avanzar en estos empeños, adquiriendo no solo conocimientos sino el placer del disfrute por el conocimiento en sí, por desentrañar secretos de la vida, por adentrarnos en la naturaleza de las cosas.

Retomando a los especialistas de la divulgación científica, se reconoce la exigencia de algunos de los que más y mejor han realizado esta actividad gozan del prestigio internacional y que por esta actividad, se han ganado el derecho a ser reconocidos por la calidad y rigor con que lo hacen.

Entre los divulgadores de la ciencia y la tecnología que tienen un espacio muy distinguido en las publicaciones científicas y que además, merecen un estudio para que nos sirva de referentes en la formación de nuevos divulgadores científicos, se pueden mencionar a Isaac Asimov, quién tiene un destacado reconocimiento en la divulgación de la astronomía y otras disciplinas científicas; Martin Gardner, destacado en la publicación de artículos de divulgación de las matemáticas. Nos resulta de mucho placer mencionar a Félix Rodríguez de la Fuente, que marcó una época en la televisión cubana [e internacional] con el programa El Hombre y la Tierra. Por su parte, Carl Sagan, fue el divulgador de la serie de televisión/el libro Cosmos: Un viaje personal, con la cual se asentó en la divulgación científica por derecho propio.

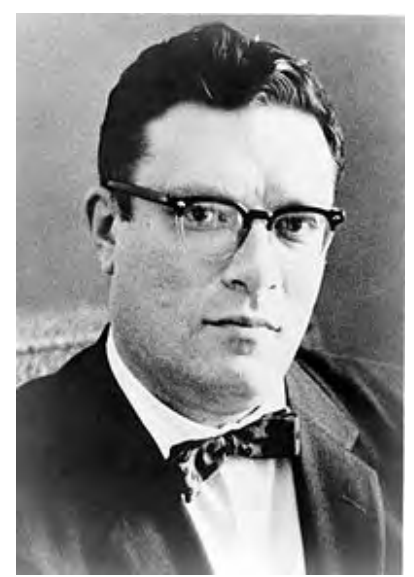

Isaac Asimov [1920-1992]

Escritor y bioquímico autor de obras de

Ciencia ficción, historia y divulgación científica.

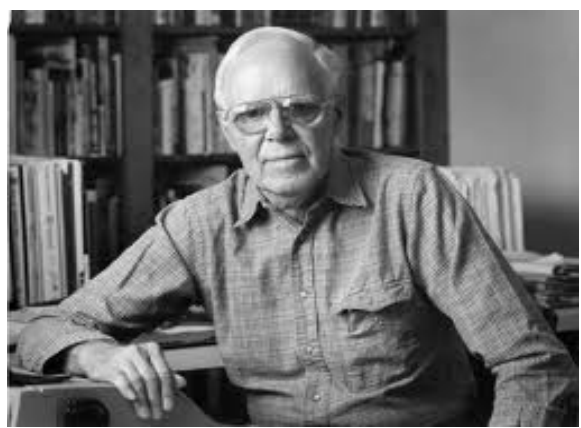

Martin Gardner [1914-2010]

Popular por sus libros de matemática recreativa. 


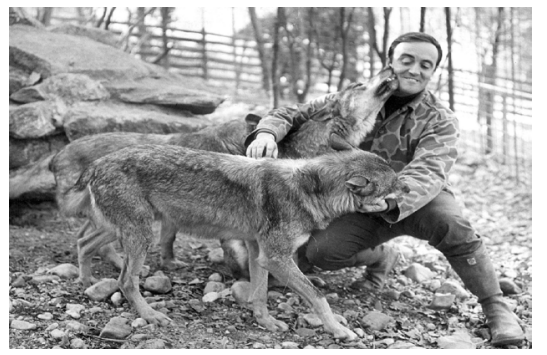

Félix Rodríguez de la Fuente- realizador de documentales para radio y televisión, destacando entre ellos la serie El Hombre y la Tierra [1974-1980].

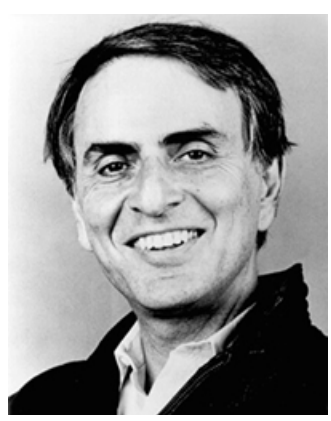

Carl Sagan [1934-1996]

\section{Divulgación científica en Cuba}

En los últimos años se han desarrollado muchas acciones que dan la medida de la comprensión yen consecuencia, de la estimulación que ha tenido la actividad de la divulgación científica, promovida desde el trabajo mismo del Ministerio de Ciencia, Tecnología y Medio Ambiente [CITMA], donde se ha estructurado un departamento para estas funciones y acciones formativas, con sus similares en cada una de las dependencias [delegaciones] ministeriales en las provincias del país.

Todo ello está en correspondencia con la concepción de que la ciencia y la sociedad constituyen un par dialéctico donde ambos se enriquecen y complementan. En su base se encuentran las ideas que sustentan una nueva ética y compromiso del sector científico con el desarrollo de la sociedad, estimuladas y estructuradas con el triunfo revolucionario de 1959, que orientan la comprensión de las necesidades sociales para el desarrollo científico - técnico.

Los antecedentes de la situación transformadora que promueve la Revolución Cubana la señala el Dr. Ismael Clark, cuando precisa que

\footnotetext{
"como resultado de las deformaciones sufrida en la etapa de la República Neocolonial, no se disponía de un potencial científico que mereciera tal denominación, pese a la existencia de precedentes y de acciones individuales que bien pueden calificarse de heroicas por lo esforzadas y solitarias de algunas figuras relevantes".
}

Por ello, se puede afirmar que con las nuevas ideas iniciales referidas al sector de la ciencia y la tecnología, se ilustra el nuevo carácter de la sociedad cubana, que adquiere la forma programática cuando el Líder de la Revolución, Fidel Castro, ante la Sociedad Espeleológica Cubana el 15 de enero de 1960 [acontecimiento que sirve de base para establecer esta fecha como Día de la Ciencia cubana], señala las nuevas concepciones del desarrollo desde la ciencia cubana; en una parte de su discurso dice:

\begin{abstract}
"El futuro de nuestra patria tiene que ser necesariamente un futuro de hombres de ciencia, tiene que ser un futuro de hombres de pensamiento," y continúa delineando la política hacia la ciencia: "...porque precisamente es lo que más estamos sembrando; lo que más estamos sembrando son oportunidades a la inteligencia..."
\end{abstract}

Son ideas que orientan el proceso de institucionalización del sector científico y da lugar al surgimiento de movimientos y organizaciones que socializan la ciencia y la tecnología, donde cada trabajador desde su puesto de trabajo, cualquiera que este sea, puede proyectar y aportar al desarrollo. Entre las nuevas estructuras funcionales aparece progresivamente la Academia de Ciencias [en su nueva etapa de desarrollo], la Asociación Nacional de Innovadores y Racionalizadores, las Brigadas Técnicas Juveniles, el Fórum de Ciencia y Técnica, etc. De ahí que la divulgación científica tenga que ser coherente con estos nuevos enfoques de participación social en el desarrollo de la ciencia y la tecnología.

Por ello, con la referida estructura ministerial se ha logrado conformar estructuras funcionales que organizan el trabajo de divulgación científica, que son el Consejo de Comunicación Social del CITMA y el Círculo de la Prensa, que complementan las acciones que se desarrollan en las instituciones educacionales tales como la literatura científica[12].

El referido Consejo se rige por principios y orientaciones nacionales del Ministerio del CITMA y atempera las acciones a las peculiaridades de cada territorio, en cuanto a las prioridades informativas, a los problemas territoriales y a las potencialidades de desarrollo de la cultura científica que ofrecen cada territorio. Concibe y desarrolla también un programa de encuentros metodológicos y de superación profesional que tienden al fortalecimiento de la identidad del desempeño profesional de los especialistas involucrados en estas actividades. 


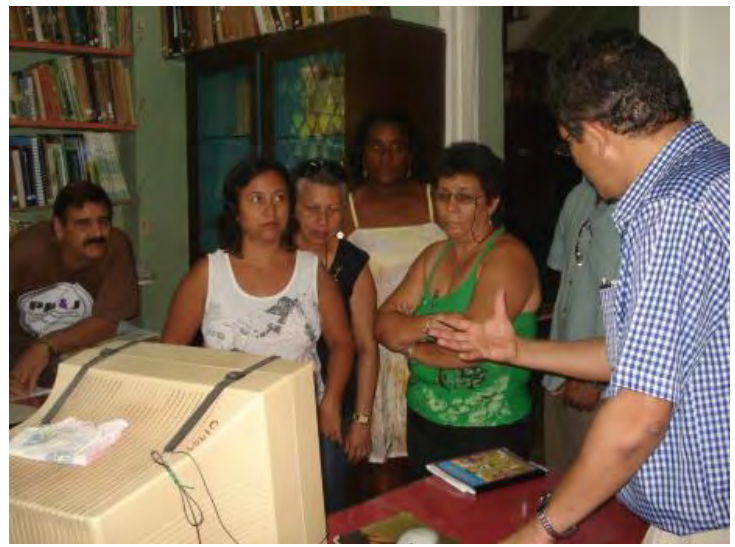

Sesión del Consejo de la Comunicación de Santiago de Cuba

en el Jardín de los Helechos, con su director al fondo, Manuel García Caluff

El Consejo de Comunicación de Santiago de Cuba está integrado por 12 especialistas que representan a los centros de ciencia y servicios científico - técnicos de la provincia, dirigidos por el especialista principal de la Delegación Territorial. Tiene la peculiaridad de que desarrolla sus actividades mensuales en un centro diferente cada mes con el objetivo de que los centros sede [del CITMA y la provincia en general] presenten la historia, estructura, membresía y resultados fundamentales, como una forma de "poblar" la cultura de los especialistas con los aspectos más esenciales de la historia y presente de la cultura científica territorial.

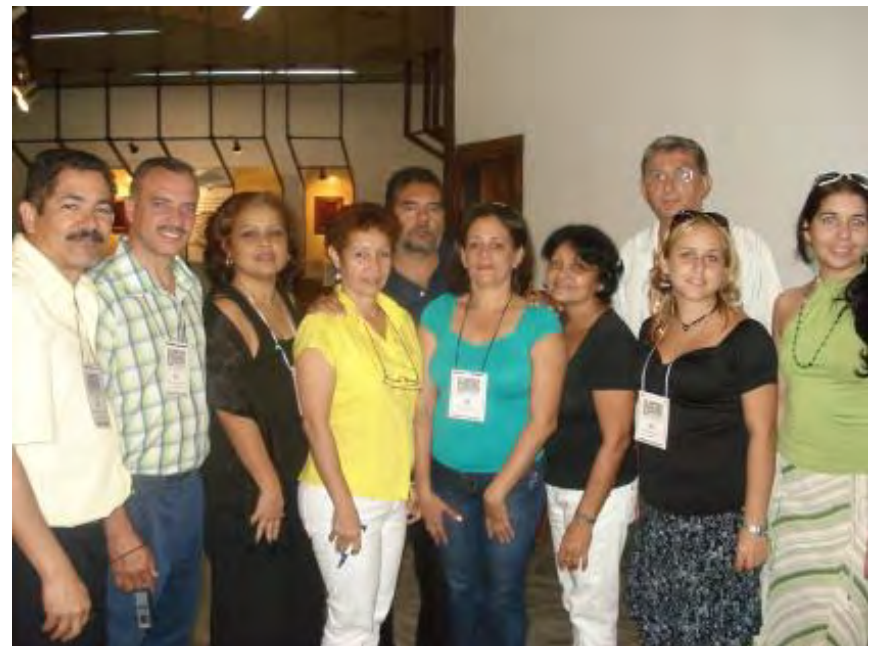

Círculo de la prensa, junto al autor del trabajo [ext. izq.]

en Salón de los Vitrales de Santiago de Cuba, Simposio de Comunicación Social.

Por su parte,elCírculodela Prensaes una estructura funcional que parte de la integración de todos los periodistas que atienden los contenidos de la ciencia, la tecnología y el medio ambiente y quelos divulgan a través de todos los medios de difusión masiva que existen en el país, tanto locales como nacionales, amén de la salida internacional que gracias a la tecnología se alcanzan en cada uno de los medios que representan. El trabajo de los especialistas principales del CITMA con el Círculo de la Prensa, es establecer una base informativa y metodológica para realizar un trabajo riguroso, serio, ético y con sólidos argumentos a través de los medios de comunicación masiva. De ahí que se realicen reuniones periódicas de información actualizada de los temas más debatidos en el país y en el mundo.
Es necesario precisar además que como parte del trabajo formativo de actualización científica en las sesiones de trabajo del Círculo de la Prensa, se desarrollan: mini conferencias y debates científicos. Se cuenta en cada caso con especialistas invitados de la comunidad científica, reconocidos expertos en cada tema abordado que van desde el comportamiento del cambio climático hasta el enfoque de ciclo cerrado en las investigaciones, desde las acciones de conservación del medio ambiente, el uso del electromagnetismo en diferentes áreas de la economía y los avances en relación a la electro medicina, hasta la posición cubana ante el uso de los biocombustibles con fines energéticos.

Resulta necesario señalar que en Cuba durante muchos años, un hombre de enorme genialidad que quería ver el desarrollo científico tecnológico de América Latina, dedicó trabajos excelente factura periodística, que son evidencia de su talento y su compromiso con la ciencia y con la sociedad. Se trata de José Martí, nuestro Héroe Nacional.

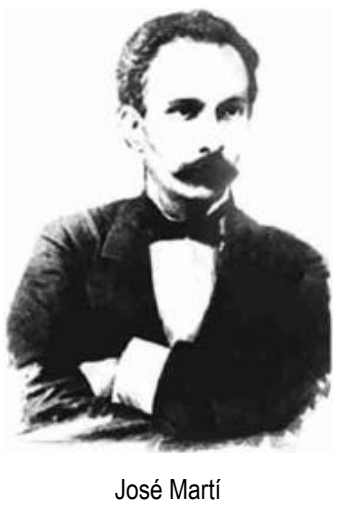

José Martí Pérez demostró que con vocación, respeto por el trabajo intelectual y tecnológico, inteligencia y profunda visión del papel de la ciencia y la tecnología en el desarrollo humano, se pueden alcanzar resultados muy sostenidos en el tiempo. Con sus crónicas mostró a los latinoamericanos el camino del desarrollo científico - tecnológico y de cómo se debía estudiar los avances que en este sentido se obtenían en el mundo capitalista para, a través de la transferencia tecnológica coherente, generar procesos auténticos y contextualizados de aceleración del desarrollo [13]. Más acá en el tiempo y como ilustración de la coherencia de pensamiento y acción, hay que considerar a Fidel Castro Ruz, líder de la Revolución Cubana, quien a través de sus discursos y diálogos con los investigadores de las diversas ramas de la economía, la salud y la cultura, mostraba al pueblo los más avanzados adelantos científicos y tecnológicos alcanzados no solo en Cuba sino en el mundo.

Los discursos pronunciados por Fidel en las actividades del Polo Científico [estructura organizativa que integra a centros de investigación a través de programas y proyectos 
de investigación], son documentos importantes para comprender los momentos y cualidades del desarrollo científico alcanzado en Cuba y también para desentrañar los avatares y resultados de la política científica nacional.

Otros divulgadores de la ciencia y la tecnología han logrado asentarse con derecho propio en la historia de la ciencia cubana. Muchos nombres se podrían mencionar, sin embargo, por razones del carácter de este trabajo solo hago referencia a José de la Osa que desde las páginas del periódico Granma publica casi diariamente sobre temas de salud; Orfilio Peláez, que escribe para el semanario [antes diario] Juventud Rebelde y por la calidad de sus publicaciones, se ha ganado el derecho a pertenecer a la asociación que agrupa a los meteorólogos de Cuba.

También mencionamos a Mara Roque, quien desde la televisión muestra con comentarios, documentales y entrevistas diferentes aspectos del estudio del medio ambiente y de la alta tecnología con sentido ecológico. Su programa Antena, ha adquirido un gran reconocimiento y teleaudiencia. Es de destacar que ella fue merecedora de un reconocimiento especial en el concurso de periodismo científico Gilberto Caballero en el año 2010, por la labor divulgativa de la ciencia, la tecnología y el medio ambiente por más de veinte años. Evento organizado por el CITMA cada año.

Asimismo, reconocemos que en la divulgación científica en Cuba se distingue la colega MSc. Mariana Sáker Labrada, quien se desempeña como Directora de Información, Informatización y Comunicación Social del Ministerio de Ciencia, Tecnología y Medio Ambiente [CITMA]. Ella, además de realizar sus funciones de dirección y coordinación en comunicación social en el CITMA, asume el guion y la conducción de un espacio televisivo que se consolida en cada semana que sale al aire. A tiempo, dedicado a tratar los temas referidos al medio ambiente, su cuidado, protección y sustentación, estimulando la cultura medioambiental de los televidentes.

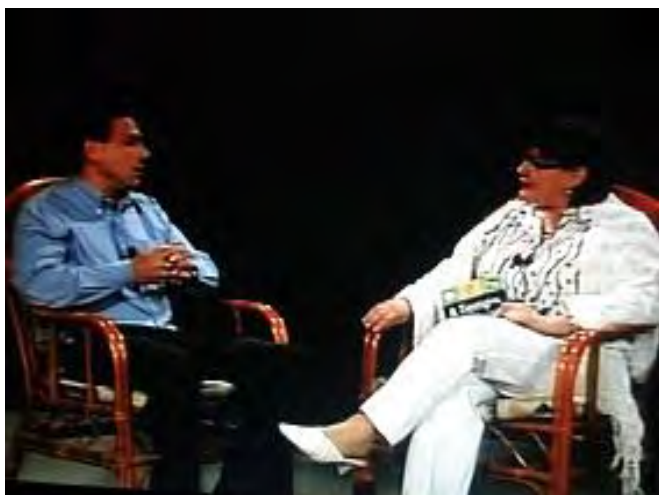

Mariana Sáker entrevista al Dr. Bladimir Moreno,

Director del Centro Nacional de Investigaciones Sismológicas

Desde su espacio presenta a muchos de los mejores especialistas sobre el medio ambiente $y$ pone al alcance de los televidentes informaciones, imágenes y valoraciones de primer nivel de comprensión acerca de los problemas actuales de la naturaleza. Por supuesto, es de esperar en un análisis como éste en Cuba, hay que hacer mención a Reinaldo Taladrid, popular periodista y conductor de programas de televisión, quien ha acaparado altos niveles de teleaudiencia a través de su programa Pasaje a lo desconocido, de Cubavisión, que se trasmite cada domingo a las 8:30 de la noche, horario que compite con otros programas más abiertos y diversos culturalmente, musicales y humorísticos, y que sin embargo, ha logrado un alto nivel de receptividad en los televidentes.

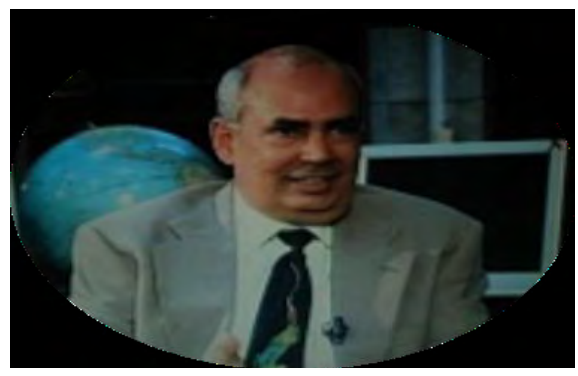

Reinaldo Taladrid

Aún más elementos y valoraciones se pueden decir de este programa y su contribución a la cultura científica de los cubanos. Solo dar a conocer en este trabajo la interactividad que ha alcanzado con los televidentes, lo que ilustra el nivel global que como sociedad ha alcanzado la educación cubana, a pesar de sus imperfecciones y demandas sociales actuales.

Todos los especialistas mencionados y otros más han sido reconocidos en diferentes momentos por su capacidad comunicativa en relación con la ciencia y la tecnología. En este contexto de análisis nos resulta muy necesario ilustrar cuáles experiencias nos pueden servir como buenos ejemplos de divulgación científica. Para ello nos auxiliamos de una búsqueda especializada y en la síntesis de algunas de las experiencias llevadas a cabo en nuestro país.

\subsection{Gultura y divulgación científica en Santiago de Cuba}

En Santiago de Cuba desde hace unos años se han ido consolidando espacios para el desarrollo de la cultura científica y aparecen otros, que son muestras del interés que cobra esta actividad desde las instituciones científicas y como expresión de la dinámica de los medios de comunicación orientados a la estimulación del conocimiento científico. De ahí que se realizan acciones que van nutriendo a la sociedad de nuevos conocimientos y aportaciones científicas.

A manera de ilustración mencionamos las siguientes, organizados por medios de prensa y por instituciones. 


\subsubsection{Medios de difiusión masiva}

\section{Televisión:}

- Expedición. Programa dirigido por Rita María Rojas y recorre la geografía territorial a través de los centros de ciencia y las investigaciones que en ellos se realizan, a través de comentarios y entrevistas a sus protagonistas o gestores. Ejemplo de los temas se cuenta el tratamiento de la biodiversidad, el patrimonio histórico de la ciudad, la aplicación de la ciencia en el tratamiento del cáncer [física nuclear y el electromagnetismo, entre otras alternativas curativas], el cuidado de los humedales, etc.

- La Historia y sus protagonistas. Es un espacio escrito y conducido por el investigador, historiador y ensayista Rafael Duharte Jiménez, quien logra desentrañar misterios de la historia a través de entrevistas realizadas a los protagonistas de los hechos que se narran. Han sido muy interesantes los programas dedicados a la arquitectura santiaguera de principio del siglo veinte, que incluye la iglesia mayor [la Catedral], en los que se destaca la labor del arquitecto Carlos Segrera.

\section{Radio}

- Programa I + D. Actualmente escrito y conducido por la periodista Cary Ferriols, trata temas de actualidad científico tecnológica sobre todo territorial y se trasmite semanalmente por CMKC Radio Revolución, emisora provincial. Alcanza una identidad informativa cada vez más reconocida, sustentada en un trabajo periodístico de gran profesionalidad realizado por la referida periodista.

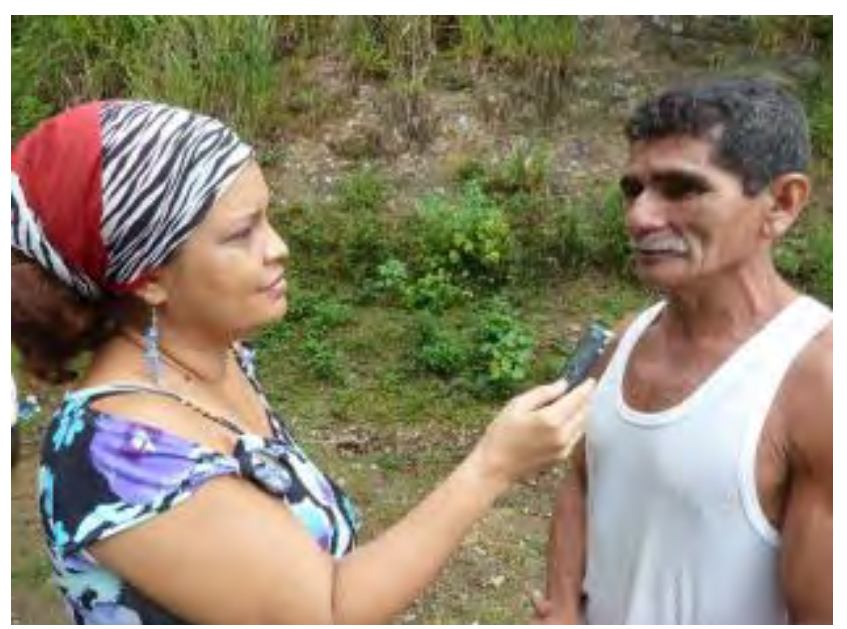

Cary Ferriols entrevista a un campesino en la Sierra Maestra.

- La ciencia entre nosotros. Surgió en julio del 2008 como espacio para dar a conocer los resultados del Proyecto 50 x 50 [Estudio y selección de 50 resultados científicos relevantes en 50 años de Revolución], a través de entrevistas a los investigadores principales de los resultados seleccionados. Por su impacto en la radio audiencia ha quedado con este mismo perfil de entrevistas pero derivado hacia temas de actualidad científica territorial.

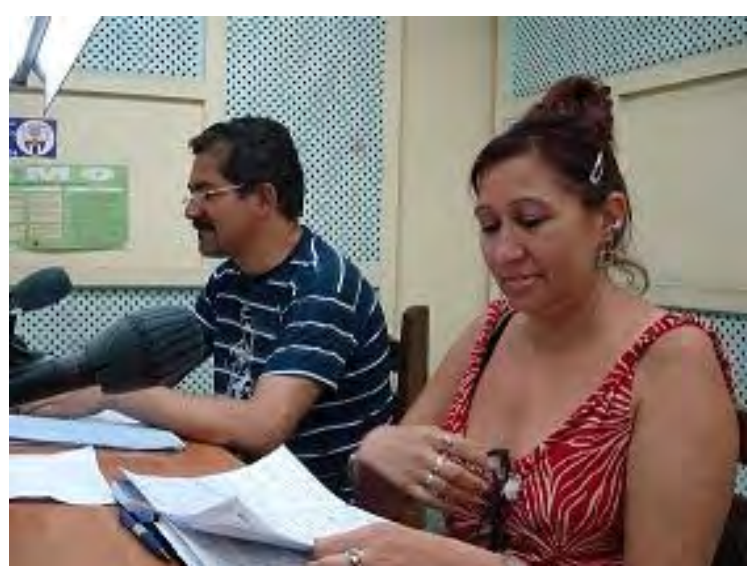

El Dr. Giovanni Villalón entrevistando a la Dra. Tania García, de la Universidad de Oriente.

En el mismo han tenido participación cerca de 150 investigadores y directivos del sector científico, entre los cuales se pueden mencionar por su valor promocional y del rigor y aprecio en la comunidad científica, la presencia de varios académicos de méritos y titulares de la Academia de Ciencias de Cuba, personalidades de las ciencias, relevantes investigadores de la capital del país, autores de premios de la Organización de las Naciones Unidas para la Alimentación y la Agricultura- FAO, premios nacionales de la salud, premios Academia a jóvenes investigadores, entre otros.

Un criterio que sirve de muestra de las valoraciones acerca de la sección es la emitida por el Dr. C. Francisco Simón Ricardo, quien fue estimulado con un Premio Internacional de la FAO por sus investigaciones acerca de la Lucha Biológica contra las plagas del cafeto. Así nos escribió en una convocatoria de valoraciones en el segundo aniversario de la sección:

\begin{abstract}
"El programa es ameno y didáctico, sin perder el rigor de la información científica con palabras amenas no rebuscadas que permita a la audición media entender los aspectos tratados. El horario es estelar por tanto desde los propios centros de trabajo los trabajadores de las ciencias y de otras esferas son radio escuchas del programa. Tal vez requiera de mayor promoción y además que no pierda la consecutividad por ninguna razón."
\end{abstract}

\subsubsection{Espacios Institucionales}

- Museo de Historia Natural Tomás Romay. Es la primera institución científica fundada por la Revolución en Oriente [1966], y brinda información y muestras sobre el origen de las especies, de la tierra y nuestro entorno más cercano. Tiene variadas exposiciones sobre plantas, animales y permite disfrutar de un plantario, con explicaciones científicas. 


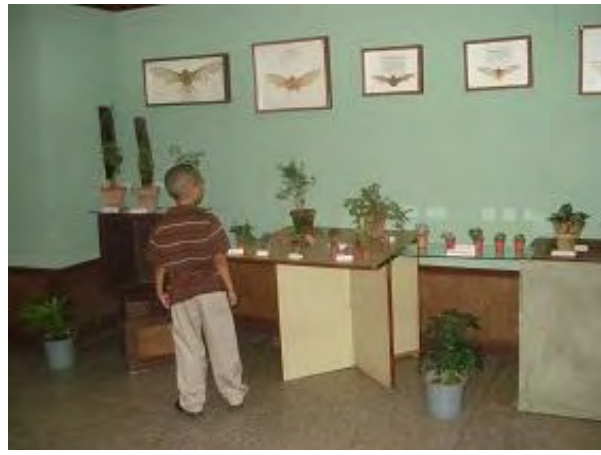

Vista del Museo Tomás Romay

\section{- Jardín de los Helechos}

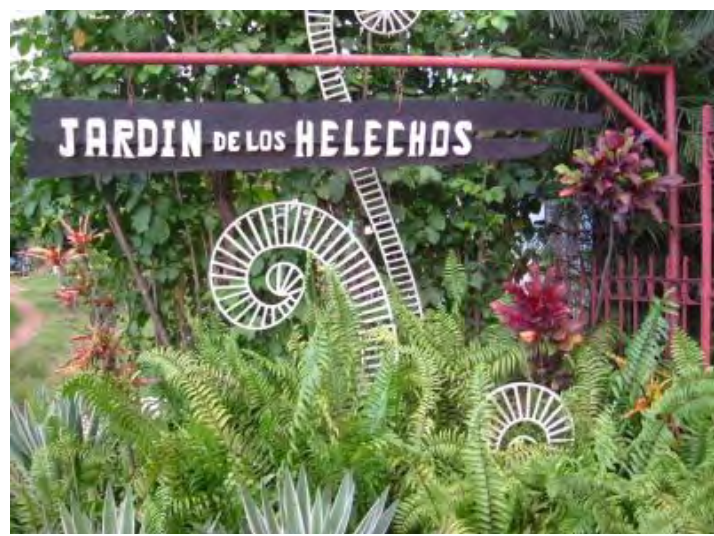

A través de casi 35 años, reúne unas 1,000 especies de plantas vivas entre las que se encuentran una de las más importantes colecciones de helechos en América, con 369 taxones infra genéricos destacándose 39 endémicos y 48 amenazados que se cultivan para facilitar su conocimiento y estudio así como para descubrir las posibilidades de su multiplicación y su posible reintroducción en las localidades donde ya desaparecieron.

Posee varios fósiles vivientes como el Psilotum y el Equisetum, con unos 350-400 millones de años de existencia, representantes de todos los ecosistemas terrestres y acuáticos incluyendo el helecho más pequeño del mundo, Azolla carolineana, conocido como "Helecho Mosquito", así como el mayor de todos, Angiopteris evecta, llamado con razón "Helecho Elefante".

También poseelaterceramásimportantecolección de orquídeas de Cuba, unas 300 especies, con representantes de todo el país y de muy diversas regiones del mundo. Entre las curiosidades que exhibe se encuentra un área dedicada a Plantas Medicinales y otra está dedicada a Plantas en Miniatura, con representantes enanos de la Piña, la Granada, el Ají, las Bromelias, etc; también un área donde se muestra la Jardinería Tradicional Cubana y el Área Martiana. Cuenta además con un Herbario de Pteridophyta, que es uno de los más importantes de Cuba y cuenta con unos 9,000 ejemplares recolectados en todo el país.
- Salón permanente de la ciencia santiaguera

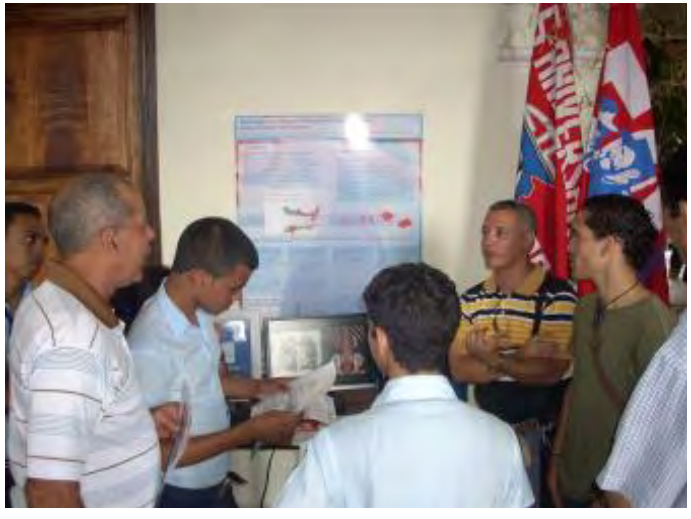

Vista de la expo del Centro de Biofísica Médica

Se estableció en el segundo piso del Centro de Información y Gestión Tecnológica [MEGACEN] y desde su inauguración se han presentado ocho exposiciones [[Resultados del Centro de Biofísica Médica, Aplicación del electromagnetismo a la salud, la agricultura y la industria [Centro Nacional de Electromagnetismo Aplicado]], La Sismología y la Meteorología al servicio de la sociedad, 50 años de la Universidad de Ciencias Médicas, entre otros.

El Salón de la Ciencia cuenta con un área expositiva permanente con los resultados y personalidades relevantes de la ciencia y la tecnología en Santiago de Cuba y un área de expo transitoria, para presentar los resultados de actualidad. Su finalidad es propiciar un espacio de interacción entre la sociedad en general y los especialistas, quienes son convocados para presentar sus temas y estimular el debate con estudiantes, trabajadores, universitarios, investigadores, etc.

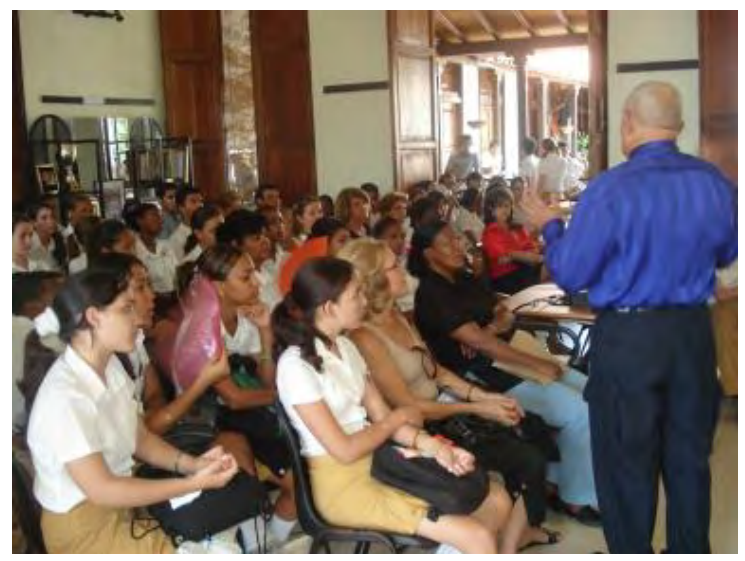

Vista de la Conferencia del Dr. José Pascual Simón.

Recibe un promedio de 450 visitantes mensuales y en él participan algunos de los mejores especialistas en diferentes temas de la ciencia y la tecnología de Santiago de Cuba, desarrollando conferencias y paneles científicos, incluyendo personalidades santiagueras de las ciencias.

\section{- Desempolvando}

Es una interesante actividad cultural que, con la finalidad de mostrar documentos y estampas de épocas remotas, organiza espectáculos en los que desfilan cantantes, declamadores, actores, magos, etc., todos recreando el tema para el cual se convoca a los espectadores. Es organizado por 
el Archivo Histórico Provincial y coauspiciado por la Dirección Provincial de Cultura.

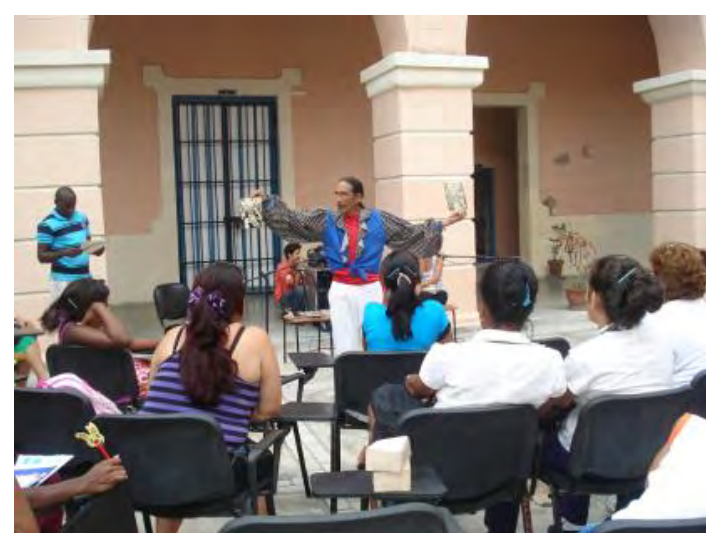

El espectáculo cultural hilvana de forma coherente y con gran calidad artística, con la participación protagónica de profesionales del arte, diferentes manifestaciones artísticas que van desentrañando diversas facetas del tema [hecho o proceso histórico - científico, tecnológico] seleccionado. Así por ejemplo se han presentado las primeras acciones de navegación aérea en Santiago de Cuba, la naturaleza original de los carnavales y más recientemente los estudios sismológicos y su impacto social en esta provincias, entre otros.

Santiago de Cuba cuenta también con sitios web en las universidades y en centros de investigación, revistas especializadas [Santiago, Ciencia en su PC, Del Caribe, etc.], y promueve diversas formas de acercarse a la ciencia y la tecnología. Muy significativo es la presencia de blogs de especialistas en divulgación científica que poco han poco se consolidan y ganan muchos adeptos y visitantes; entre ellos se cuenta a Noel Pérez García [especialista de comunicación del Centro de Electromagnetismo Aplicado], José Roberto Loo Vázquez [periodista de Rabio CMKW Radio Mabí] y Coral Vázquez [periodista de Tele Turquino].

Las asociaciones y organizaciones científicas no gubernamentales en el territorio santiaguero, también instrumentan cursos de superación sobre el tratamiento de su objeto social referido a la divulgación científica. Por ejemplo, recientemente como Cubasolar [Organización no gubernamental dedicada al estudio y difusión de las fuentes renovables de energía] desarrolló un curso para divulgadores científicos acerca del tratamiento de dichas fuentes energéticas, muy bien valorado por los participantes, entre los que se encontraban periodistas, profesores, especialistas de comunicación social del CITMA y estudiantes de comunicación social de la Universidad de Oriente.

Como resultado de la labor del proyecto Historia de la Ciencia y la Tecnología en Santiago de Cuba se lleva a cabo un fuerte movimiento por la sistematización de la cultura científica con énfasis en lo territorial, que se sustenta en estudios de los procesos que al interior de las instituciones, organizaciones se han llevado a cabo, así como la determinación de labor individual de los investigadores.

En todo este ambiente cultural se determinaron las personalidades de las ciencias de Santiago de Cuba, las cuales constan con el reconocimiento oficial de la comunidad científica y de las direcciones institucionales territoriales. Todos ellos se convierten en fuente de divulgación científica que adquiere matices cada vez más sistémicos.

Una acción que demuestra lo anterior es la determinación del Sendero de las Personalidades de las Ciencias en el cementerio Santa Ifigenia, de Santiago de Cuba, que muestra el camino funcional para recordar a aquellos investigadores con tales consideraciones de reconocimientos en las tumbas donde yacen sus restos mortales en el cementerio de la ciudad.

Este recorrido es asumido con más compromiso por las instituciones y organizaciones y tiene la particularidad, de que a él se han involucrado a estudiantes de preuniversitario integrados en una sociedad científica dedicada al estudio de las Personalidades de las Ciencias y a su presentación en el sendero descrito.

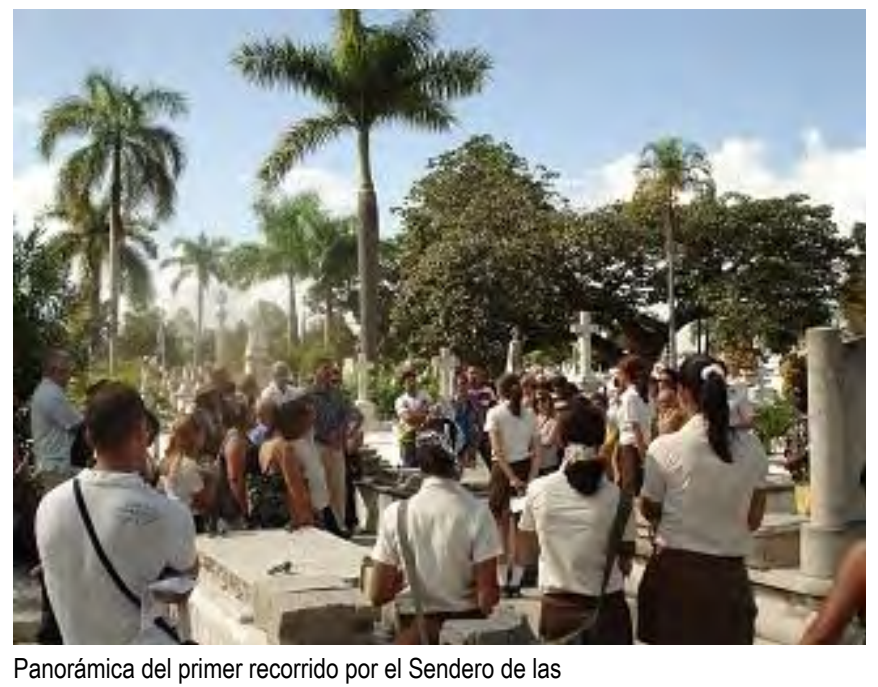

Personalidades en el cementerio Santa Ifigenia.

Por otra parte, instituciones científicas como las universidades [ 6 en total] de Santiago de Cuba y MEGACEN [nombre comercial del Centro de Información y Gestión Tecnológica provincial dedicado a la asesoría a los investigadores, directivos y en todos los temas referidos a la ciencia, la tecnología, la innovación y la propiedad industrial, entre otros], promueven y desarrollan cursos de ciencia con creciente participación de profesionales de todos los ámbitos de trabajo.

Recientemente se realizó un curso de postgrado sobre este tema a un grupo de 18 periodistas santiagueros, fruto de la colaboración de la filial de la Unión de Periodistas, el CITMA y la Carrera de Comunicación Social de la Universidad de Oriente. En el mismo se trataron temas teóricos interesantes y sobre todo, se logró actualizar sobre la estructura y funcionamiento del CITMA, las prioridades de la divulgación científicas y los principales avances que en este campo se han 
logrado en la provincia. Sin embargo, aún quedan en los sueños por realizar, la acreditación de una maestría sobre comunicación y divulgación científica. Los esfuerzos realizados hasta el momento no se han visto coronados con el éxito.

\subsection{Modelo de divulgación por una cultura científica en Santiago de Guba}

A nivel territorial como lo es Santiago de Cuba como provincia, que además tiene una historia cada vez más sistematizada sobre la ciencia y la tecnología en su devenir, necesita tener un modelo organización de divulgación por una cultura científica. Dicho modelo deberá integrar acciones en varias direcciones.

Por contenidos: Ciencia universal, Ciencia nacional, Ciencia territorial En cada caso sistematizar aportes renovadores de las ciencias, las instituciones y personalidades aportadoras.

\section{Por áreas de sistematización:}

- Nivel institucional. Comunidad científica, Sistema educativo general, Sistema de educación superior.

- Nivel social. Los medios de prensa, Instituciones sociales.

En cada caso se instrumentarán acciones que dinamizarán la cultura científica en las direcciones señaladas. Entre ellas se pueden contar:

- Clases, actividades extra clases y extraescolares.

- Recorridos científicos - culturales.

- Conferencias especializadas.

- Debates científicos sobre temas de actualidad.

- Eventos científicos.

- Talleres científicos.

- Cursos, diplomados, maestrías y doctorados.

La comprensión de estas necesidades culturales [científicas] nos llevará a mejorar la dinámica en las clases, a realizar concursos con carácter científico, creativos y enriquecedores de la cultura general con base en la ciencia, en la profundidad del pensamiento y orientado hacia la búsqueda de soluciones a los problemas del entorno más cercano.

\section{Temas a debatir}

Quedan muchos temas a debatir en los próximos años, entre ellos:

- Percepción de la ciencia y la tecnología en los diferentes grupos sociales: niños, adolescentes, jóvenes y adultos así como en la comunidad científica.
- Sistematización de la cultura científica en los diferentes niveles de las instituciones educacionales.

- Nivel de efectividad de las acciones de estimulación de la cultura científica en la sociedad.

- Caracterización profesional del divulgador de la ciencia.

- Didáctica de la divulgación de la ciencia.

-Formación del divulgador de la ciencia.

\section{CONCLUSIONES}

La divulgación científica se abre paso cada vez más sustentadas en la necesaria relación intrínseca entre la ciencia y la sociedad.

Las formas de divulgación son muy variadas y están a merced de la creatividad de los profesionales de esta materia.

La divulgación de la ciencia puede ser una ocupación de muchos profesionales, no está restringido a los periodistas y a los científicos. Sin embargo, en todos ellos debe primar el dominio de los contenidos, la veracidad de la información y el respeto por las fuentes originarias.

Santiago de Cuba alberga un gran potencial para desarrollar importantes proceso de comunicación y divulgación científica. Lo confirma su potencial científico, dado en más de 600 doctores en ciencias, seis universidades, más de treinta centros de investigación y una gran cantidad de profesionales ligados a los procesos de investigación y de la formación de las nuevas generaciones.

Las acciones de divulgación científica logrados en Santiago de Cuba pueden constituirse en una plataforma, desde donde se sistematicen concepciones y enfoques del trabajo de divulgación científica.

\section{BIBLIOGRAFÍA}

Agencia ID. OEI-AECID. Avanza la divulgación de la ciencia en América Latina, pero debe ser más crítica y regionalizada. Posted on abril 28,2011 by nobelpg| Consultado el día 11 de mayo de 2011.

BARTELLINI, María de los Ángeles. La divulgación científica y la comunicación en el aula: Profesorado de Cs. Biológicas. Didáctica [1952]. Universidad Nacional de Río Cuarto. [Consultado 9 de mayo 2011]

CALVO HERNANDO, M. Conclusiones para un libro de divulgación. Año: 2006.

El Periodista toca la puerta del siglo XXI [Convenio Andrés Nello, Bogotá, 1998. Seminario-Taller sobre Difusión y Divulgación del Conocimiento, 
Universidad Autónoma del Estado de Morelos, México, 1983.

Divulgación y Cultura Científica Iberoamericana: Avanza la divulgación de la ciencia en América Latina, pero debe ser más crítica y regionalizada. Ads by Google. TDW Magnetic Cylinders. Magnetic printing and die cutting cylinders for any press www.magneticcylinders.com [Revisado el 22 de mayo 2011]

GOCHE, Flor. En riesgo, la divulgación de la ciencia en la UNAM. 14 Abril 2011. Sección: Educación [Consultado 10 de mayo 2011]

GONZÁLEZ SUÁREZ, E. Conocimiento científico e información científica. http//bvs.sld.cu/revistas/ aci/vol14-6-06/aci03606.htm\#cargo. [Consultado 8 de mayo 2011]

MUÑOZ, Emilio. La cultura científica, la percepción pública y el caso de la biotecnología. Grupo Ciencia, Tecnología y Sociedad. Unidad de Políticas Comparadas CSIC, Madrid. Ponencia presentada en el seminario La cultura científica en la sociedad de la información [Oviedo, 30 de mayo a de junio de 2002], organizado por el Observatorio de Cultura Científica de la Universidad de Oviedo.

"Líneas generales de un programa nacional de difusión de la ciencia al público", [Ponencia presentada en el V Congreso Iberoamericano de Periodismo Científico, Valencia, 1990].

LÓPEZ, José A. SEBBM divulgación. La ciencia al alcance de la mano. Las tres ramas de la Cultura Científica. http://www.sebbm.es/ES/divulgacionciencia-para-todos_10/la-ciencia-al-alcancede-la-mano-articulos-de- divulgacion_29. [Consultado 10 de mayo 2011]

MARTÍ, José. Obras Completas, T.7, pág. 149.

MARTÍN, Serrano Manuel. [1994]: "La Producción Social de Comunicación". Editorial Alianza. México.

SEMIR, Vladimir de, [2007] "La divulgación científica es estratégica". "Cafés científicos" y "Visiones de la ciencia". Barcelona, pág. 28 - 29. [Internet, revisado 22 mayo 2011]

PÉREZ TAMAYO, R. Sobre la divulgación científica en México. [9 de agosto de 2011]

VICTORIANO, F [2011]. Apuntes sobre ciencia y comunicación. El caso de la divulgación científica. XIII Encuentro Nacional AMIC 2011, Pachuca, Hidalgo - Memoria. Mesa comunicación de la ciencia.

VILLALÓN GARCÍA, G. [2009] Experiencias en la divulgación científica en Santiago de Cuba. Simposio Internacional sobre Educación y Cultura en Iberoamérica. Universidad de Ciencias Pedagógicas de Matanzas.

VILLALÓN GARCÍA, G. [2010] Didáctica e impacto cultural de la sección La ciencia entre nosotros.
Informe de investigación. Delegación Territorial del CITMA. Santiago de Cuba, 2010.

WEIL Pascale. [1992]: “La Comunicación Global. Comunicación Institucional y de Gestión". Editorial Paidós. Barcelona.

ZAMARRÁN GARZA, G. Posibles significados de divulgar la ciencia. En: Trilles, Irene y Miriam Rodríguez. La Comunicación de la Ciencia y la Tecnología: una visión universitaria. La Habana: Editorial Pablo de la Torriente, 2005.- - p. 28-38.

\section{Notas}

[1] Martí, Obras Completas, T VII, p. 149.

[2] Villalón, 2009:2.

[3] Semir, 2007:28

[4] Goche, 2011:2

[5] Idem

[6] Calvo, 2006:1

[7] Estrada, 2006:3

[8]DivulgaciónyCulturaCientíficalberoamericana, 2011:1

[9] Idem

[10] Goche, 2011:2

[11] Pérez Tamayo, 2011:2

[12] El Consejo de Comunicación Social está conformado por los especialistas que desarrollan estas funciones en todos los centros adscritos a las Delegaciones Territoriales del CITMA [en cada provincia], además de especialistas que por su contenido de trabajo es necesario que participen en el mismo así como representantes de organizaciones que se encargan de la ciencia y la tecnología, dígase el FORUM de Ciencia y Técnica [estructura que organiza la actividad de innovación e inventivas y promueve encuentros para la generalización de los resultados] las Brigadas Técnicas Juveniles [organización que integra a los jóvenes que desarrollan la actividad investigativa - innovativa en los centros de trabajo], y la Asociación Nacional [provincial en este caso] de Innovadores y Racionalizadores [ANIR], que aglutina a los trabajadores que realizan la importante labor de encontrar soluciones prácticas a los problemas tecnológicos de las fábricas u otros centros laborales, como respuestas a las limitaciones para la compra de piezas de repuestos.

[13] Disfrutemos de la siguiente selección de extractos de artículos escritos por José Martí y observemos sus presiones y solidez científicas, comprensible para todos, por demás. 
"El hombre no es un soberbio ser central, individuo de especie única, a cuyo alrededor giran los seres del cielo y de la tierra, animales y astros; sino la cabeza conocida de un gran orden zoológico. [ OC. t.15 p.194]

"Todo es hermoso y constante,

Todo es música y razón,

$\mathrm{Y}$ todo, como el diamante,

Antes que luz, es carbón." [OC.t.16p.65]

"Aquella exhibición habrá convencido a los ganaderos de que el éxito de los expositores uruguayos que obtuvieron premio, fue debido al cuidado extremo puesto, y a los juiciosos medios empleados en el cruzamiento de ganado, de manera que se acomoden los diferentes cruzados a las condiciones especiales del pasto del país y el clima."[OC.t. 28 p. 207]

\section{Para citar este artículo:}

VillalónGarcía,GiovanniL. (2012).IFUNDAMENTOS Y EXPERIENCIAS DE LA DIVULGACIÓN CIENTÍFICA EN SANTIAGO DE CUBA. Revista Luciérnaga, Año 4, N8. Grupo de Investigación en Comunicación, Facultad de Comunicación Audiovisual, Politécnico Colombiano Jaime Isaza Cadavid. Medellín-Colombia. ISSN 2027-1557. Págs. 35-50.

DOI. 10.33571/revistaluciernaga.v4n8a2 